\section{Les rencontres RARE 2017 vues du point de vue des professionnels de santé et de recherche}

Ségolène Aymé
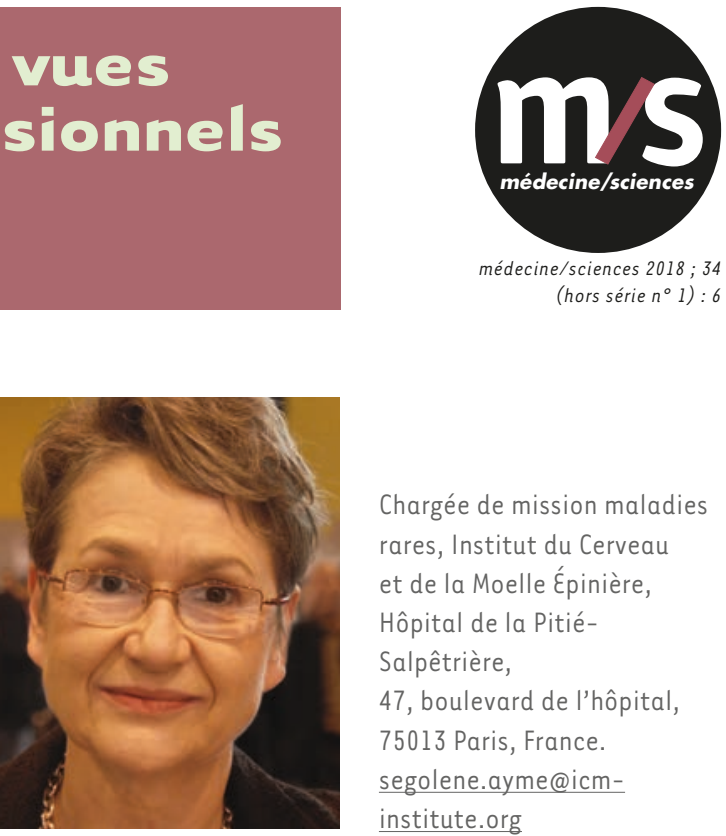

Chargée de mission maladies rares, Institut du Cerveau et de la Moelle Épinière, Hôpital de la Pitié-

Salpêtrière, 47, boulevard de l'hôpital, 75013 Paris, France. segolene.ayme@icminstitute.org

organisée et formatée requiert des efforts considérables de la part de ceux qui les saisissent. Les cliniciens sont bien souvent mis à contribution, en surplus de leur travail clinique, d'où les échecs relatifs de plusieurs initiatives par le passé. II faut trouver d'autres façons d'utiliser les données disponibles, sans nouvelle saisie. La recherche sur les maladies rares n'a pas de sens au niveau national : la France doit se joindre aux nombreux efforts internationaux en la matière.

Enfin, l'objectif est de ne plus perdre la moindre opportunité pour les patients. II faut donc joindre les intérêts convergents des acteurs. Nous ne pouvons plus avoir d'actions purement publiques ou industrielles, mais nous devons partager tout ce qui peut l'être, définir des outils précompétitifs pour les industriels et réaliser ces actions avec des financements dignes de ce nom.

Certes, nous attendons beaucoup des décisions ministérielles, mais l'important est ce que nous faisons chacun au quotidien pour faire avancer les dossiers qui nous concernent. $\diamond$

The RARE 2017 meeting from a health professional perspective

\section{LIENS D'INTÉRÊT}

L'auteur déclare n'avoir aucun lien d'intérêt concernant les données publiées dans cet article. 